\title{
Perinatal risk factors for asthma in Finnish adolescent twins
}

\author{
Maija Räsänen, Jaakko Kaprio, Tarja Laitinen, Torsten Winter, Markku Koskenvuo, \\ Lauri A Laitinen
}

\begin{abstract}
Background-Previous studies have suggested that, in addition to genetic liability and environment in early childhood, intrauterine life also influences the risk for asthma beyond childhood. Low birth weight, prematurity, young maternal age, and maternal smoking have all shown an association with asthma. The effect of perinatal factors on the risk for asthma in relation to familial and social risk factors was studied in a nationwide population-based sample of adolescent twins. In addition to a distribution of birth characteristics among twins which differs from that of singletons, data on twins enable a distinction to be made between genetic and environmental sources of variation.
\end{abstract}

Methods-Questionnaires were sent to five consecutive birth cohorts of Finnish 16 year old twins born in 1975-9 and to their parents (3065 families). The outcome measure was life time prevalence of doctor-diagnosed asthma in these adolescents. The association between asthma and potential risk factors was assessed by multiple logistic regression and discordant twin pair analysis.

Results-Risk for asthma increased with increasing ponderal index ( $p$ for trend $<0.01$ ) and decreasing maternal age ( $p$ for trend $<0.05$ ). Among the $25 \%$ of twins with the highest ponderal index, the odds ratio for asthma was 1.82 (95\% confidence interval 1.18 to 2.79 ) compared with those in the lowest $25 \%$. Neither birth weight, gestational age, nor Apgar score was associated with asthma. When perinatal risk factors were combined with familial and social risk factors, ponderal index, maternal smoking, parental asthma, and sibship size were all significant independent determinants of asthma in these adolescents.

Conclusions-The risk for asthma in adolescent twins increases with increasing ponderal index when adjusted for familial and social factors.

(Thorax 2000;55:25-31)

Keywords: asthma, perinatal factors, twins

Previous studies have shown that factors acting prenatally and in early childhood may predispose to chronic diseases in adult life. Characteristics of the newborn infant reflecting the intrauterine environment, particularly nutritional status of the fetus, have also been shown to be associated with respiratory impairment in later life. ${ }^{1-3}$ Low birth weight has been associated with asthma in some studies ${ }^{4-6}$ but not in others. ${ }^{27}$ Prematurity, especially pulmonary prematurity requiring mechanical ventilation, is also a risk factor for wheezing illness in childhood. ${ }^{89}$ Other factors related to the well being of the developing child, such as young maternal age, maternal smoking, parental asthma, and male gender, have been reported to increase risk for asthma in some studies but not all. $^{57910}$ Interestingly, associations between perinatal factors and other atopic manifestations have shown somewhat opposite trends from those of asthma. Large head circumference, high gestational age, and high maternal age have been reported to increase the risk for hay fever, ${ }^{511}$ atopic eczema, ${ }^{12}$ or high serum $\operatorname{IgE} .^{13}$

Twin pregnancies differ from singleton pregnancies in several respects. Twin mothers, especially of dizygotic (DZ) twins, tend to be older and of higher parity. ${ }^{14}$ Duration of gestation is shorter, twins are of lower birth weight, and their neonatal mortality is higher than that of singletons. ${ }^{14}{ }^{15}$ Over $40 \%$ of twins are born preterm (before 37 weeks) and around 50\% weigh less than $2500 \mathrm{~g}$ at birth. ${ }^{14}$ Twins show accelerated maturation of the lungs compared with singletons ${ }^{16}$ but no major differences in neonatal outcome have been shown between twins and singletons of similar gestation. ${ }^{17}$ Differences may also exist in the intrauterine environment-for example, due to differential placentation or twin-twin transfusion-and may lead to differences in birth characteristics within the pair. ${ }^{18}$ By the use of these differences, the association between asthma and birth characteristics can be assessed by analysis of discordant pairs.

We studied the effects of perinatal factors on the risk for asthma in a nationwide cohort of adolescent twins and examined the effects of perinatal factors in relation to familial and social risk factors for asthma. In addition, we wanted to assess the association of perinatal factors and asthma in a population with a different distribution of birth characteristics and to examine whether genetic factors affect the contribution of perinatal factors to asthma.

\section{Methods}

STUDY DESIGN

The characteristics of the study population and zygosity determination have been described in detail previously. ${ }^{19}$ Briefly, for the FinnTwin 16 study Finnish families with twins born in 1975-9 were identified from the Finnish Central Population Registry which holds records for practically all twins born in Finland during that 
period. In 1991-5 3065 families in which both twins were alive and residing in Finland were mailed questionnaires within two months of the 16 th birthday of the twins. Both parents and both co-twins were mailed a personal questionnaire in addition to a family questionnaire about the birth and development of the twins.

The parents were asked whether the first born, second born, neither, or both of the twins had been diagnosed as having either asthma or hay fever by a doctor. They were also asked for the birth weight, length at birth, and Apgar score of the twins, the gestation week at which the twins were born, and whether the twins had to stay in hospital after birth. Further, the parents were asked whether they themselves had been diagnosed as having either asthma or hay fever by a doctor, how many children they had older than the twins, their own occupation, their smoking habits, and whether or not they smoked indoors when the twins were under school age. The twins replied to questions concerning their own smoking habits. Of the 3065 families, $83 \%$ ( $\mathrm{n}=2550$ ) returned the family questionnaire and, for those, asthma data were available for $90 \%$ of the adolescents $(n=4578)$.

A detailed smoking history was obtained from both the parents and the adolescents but, for the purpose of this analysis, dichotomised smoking variables were used. ${ }^{20}$ Parents who had smoked fewer than 5-10 packets of cigarettes during their lives were classified as non-smokers, and those who had smoked more were regarded as ever smokers. ${ }^{21}$ Those adolescents who had never smoked or had smoked at most 50 cigarettes during their lives were classified as non-smokers. Those who had smoked more were classified as smokers at the age of 16. Exposure to environmental tobacco smoke (ETS) was considered present if the mother reported that at least one person had smoked indoors at home when the twins were under school age (age of seven). The father's occupation at the time of the survey was grouped according to the classification of the agency, Statistics Finland: (1) farmers, (2) other self-employed persons, (3) upper level employees, (4) lower level employees, (5) manual workers, and (6) others including students and pensioners. ${ }^{22}$

Because the Finnish Medical Birth Registry was not launched until 1987, we had to rely on parental reporting of birth data. Compared with register ascertained birth data, there may have been inaccuracies in parental reporting. However, maternal reports of birth weight and gestational ages have shown very good agreement with medical records, ${ }^{23}$ and birth weights of the twins participating in the study are well in accordance with the birth statistics of multiples born in Finland during that period. ${ }^{24}$ In addition, mothers may have used their maternity cards to recall birth data; in Finland relevant information on pregnancy, delivery, and the newborn infant is recorded by maternity health care nurses, midwives, and doctors on a personal maternity card returned to the mother at the last check up visit (around 12 weeks post partum). In order to increase reliability, data on perinatal measures were examined for outliers and rechecked if necessary from the original questionnaires. Lengths of gestation over 42 weeks were excluded as implausible (four pairs). Data on gestation was missing for 287 pairs. If the parents replied that they could not recall the gestational age, it was recorded as 37 weeks (median gestational age) but only if birth weight and length were available (10 pairs). Gestational age was excluded in 61 pairs in which mean birth weight within the pair was more than three standard deviations (SD) over the mean birth weight for Finnish preterm singletons at the reported gestational age but the birth weights were in accordance with the reported birth lengths. In three pairs only birth length, and in four pairs birth weight, length and gestational age were excluded as implausible.

Because birth weight distribution among twins is different from among singletons, relative measures of birth weight are probably more descriptive of the intrauterine well being in twins than is absolute birth weight. ${ }^{14}$ The ponderal index is a measure of fatness or thinness, often used as an index of nutritional status at birth. The ponderal index was calculated as birth weight $(\mathrm{kg})$ divided by the cube of birth length $\left(\mathrm{m}^{3}\right) .{ }^{25}$ Gestation adjusted birth weight was calculated by subtracting from the twin's birth weight the mean birth weight of all twins born at the same week of gestation and dividing this difference by the latter. This variable was then divided into fifths and grouped into three categories (lowest, second to fourth, and highest).

\section{ANALYSIS OF DATA}

Logistic regression analysis was used to calculate odds ratios (OR) for asthma in the adolescents separately for perinatal and non-perinatal variables. Odds ratios with $95 \%$ confidence intervals (CI) were first calculated for each categorised perinatal variable: birth weight, ponderal index, gestation adjusted birth weight, Apgar score, neonatal hospital admissions (all unique to each individual), gestational age, and maternal age (common to both twins in each pair). Each variable was adjusted with the zygosity of the twins (monozygotic/dizygotic), birth order (first born, second born), sex, number of older siblings (0-1, 2 or more), parental asthma (no, yes), and maternal smoking ever (no, yes). The variables unique to each individual were additionally adjusted for the corresponding measurement in the co-twin in order to assess the effect of the growth pattern in the co-twin. For the adjusted regression models cases with data available on all factors in each model were included.

Because we have previously shown heterogeneity in liability to asthma by parental asthma status ${ }^{19}$ possible interactions between perinatal variables and parental asthma were tested. We performed analysis on data stratified by parental asthma status: (1) families with at least one asthmatic parent $(n=156)$ and (2) families with unaffected parents $(n=1857)$. Because both parents were affected in only eight families, these were pooled into families with one affected parent. When testing the sig- 
nificance of interactions, perinatal variables were entered in the model in turn as categorised or categorised but treated as continuous with assigned rank $(1,2,3 \ldots$. etc.).

Univariate analysis on non-perinatal variables unique to each individual - that is, sex, hay fever in the adolescent, and the adolescent's own smoking - or common to both twins - that is, parental asthma, parental hay fever, number of older siblings, father's occupation, maternal smoking, and ETS - were first performed to obtain crude ORs with 95\% CI values for the risk for asthma. Non-perinatal variables were then included in one model and simultaneously adjusted firstly for factors in the model other than hay fever in the adolescent and then, in addition, for hay fever.

Those perinatal and non-perinatal risk factors with significant or nearly significant $(\mathrm{p}<0.2)$ Wald statistics were then included in a single model and backward stepwise logistic regression was performed (removal of variables based on the probability of the likelihood ratio statistic, $p>0.1$ ) in order to obtain the most parsimonious model.

Population attributable proportions were calculated for each variable independent of the exposure to the other variables as the proportion of cases due to exposure to the risk factor among all those exposed and unexposed. ${ }^{26}$ For variables with several categories the category of interest was regarded as the exposure category and the others as unexposed.

Discordant pair analysis in twins can be used to study the determinants of an outcome. ${ }^{27}$ The association between an exposure and the outcome can be estimated by the magnitude of the intrapair difference in the exposure variable among twins discordant for that outcome. The genetic versus environmental nature of the association can be estimated by comparing the intrapair differences in monozygotic (MZ) and $\mathrm{DZ}$ twins. ${ }^{27} \mathrm{MZ}$ and $\mathrm{DZ}$ twins discordant for asthma were identified. Among the pairs the difference in birth weight, ponderal index, and Apgar score was calculated separately for $M Z$ and DZ twins by subtracting that of the non-asthmatic co-twin from that of the asthmatic co-twin. The significance of the median differences was tested by the Wilcoxon signed rank test. The differences in the $M Z$ twins were compared with the differences in the $\mathrm{DZ}$ pairs by the Wilcoxon rank sum test. Categorised birth weight, ponderal index, and gestation adjusted birth weight and neonatal hospitalisa-

Table 1 Mean (SD) perinatal characteristics of 16 year old Finnish twins

\begin{tabular}{|c|c|c|c|}
\hline & $\begin{array}{l}\text { Total no. of } \\
\text { adolescents }\end{array}$ & $\begin{array}{l}\text { Adolescents } \\
\text { without asthma }\end{array}$ & $\begin{array}{l}\text { Adolescents } \\
\text { with asthma }\end{array}$ \\
\hline Birth weight (g) & 4502 & $2669(523)$ & $\begin{array}{l}2707(556) \\
\mathrm{n}=177\end{array}$ \\
\hline Length at birth $(\mathrm{cm})$ & 4407 & $47.2(2.8)$ & $\begin{array}{l}47.1(2.6) \\
\mathrm{n}=174\end{array}$ \\
\hline Ponderal index $\left(\mathrm{kg} / \mathrm{m}^{3}\right)$ & 4403 & $25.2(2.9)^{\star}$ & $\begin{array}{l}25.8(3.3)^{\star} \\
\mathrm{n}=174\end{array}$ \\
\hline Gestational age (weeks) & 3968 & $37.0(2.6)$ & $\begin{array}{l}37.2(2.7) \\
\mathrm{n}=155\end{array}$ \\
\hline Apgar score & 3710 & $8.3(1.8)$ & $\begin{array}{l}8.1(2.2) \\
\mathrm{n}=140\end{array}$ \\
\hline Maternal age at birth of twins (years) & 4578 & $28.3(5.0)^{\star}$ & $\begin{array}{l}27.5(4.5)^{\star} \\
\mathrm{n}=179\end{array}$ \\
\hline
\end{tabular}

${ }^{\star}$ Statistically significant difference between the groups $(\mathrm{p}<0.05)$. tion of asthmatic co-twins were compared with those of non-asthmatic co-twins by $\mathrm{McNe}-$ mar's two-sided test.

Analyses were computed with SPSS, Release 7.5.1. and SAS, Release 6.12. Differences in continuous variables between asthmatic and non-asthmatic groups were compared by the $t$ test for independent samples and in dichotomous variables by the $\chi^{2}$ test. The test for trend within variables with several categories was performed with logistic regression. Each category with an assigned rank $(1,2$, etc) was entered in the model as a continuous variable. The Wald statistic obtained served as the test statistic with its significance level serving to assess significance for trend. In similar fashion, perinatal variables were entered in the regression model when testing interactions between individual perinatal variables and parental asthma. Because individual observations on twins selected as pairs may not be regarded as totally independent, generalised estimating equations (GEE) were used in the regression analysis to correct for the lack of independence (SAS Proc Genmod). ${ }^{28}$

\section{Results}

The cumulative incidence of asthma in the adolescents was $3.9 \%$ (179 affected of 4578 twins with asthma data available). Comparison of their perinatal characteristics showed that asthmatic adolescents had a slightly higher mean ponderal index $(p<0.05)$ and their mothers were younger at their birth $(p<0.05)$ than was the case for unaffected adolescents (table 1). Of the asthmatic adolescents $34.5 \%$ had been admitted to hospital during the neonatal period compared with $29.3 \%$ of the nonasthmatic subjects. No significant differences were found when mean values for perinatal variables in those responding to the asthma question were compared with those of nonresponders, except for higher maternal age in the families of non-responders (28.2 years versus 29.1 years, $\mathrm{p}<0.001, t$ test).

In the univariate analysis of categorised individual perinatal factors the risk for asthma increased with increasing ponderal index (table 2). Among those in the highest $25 \%$ of the ponderal index the risk for asthma was $82 \%$ higher than in those in the lowest $25 \%$. Assuming the median birth length for both twins to be $47 \mathrm{~cm}$, the mean ponderal index in the lowest and highest groups corresponded to length adjusted birth weights of $2260 \mathrm{~g}$ and $2970 \mathrm{~g}$. This in turn corresponds to an increase of approximately $10 \%$ in the risk per $100 \mathrm{~g}$ increase in birth weight. A high ponderal index remained a significant risk factor after adjustment for confounding variables (table 2). The risk of asthma also increased with gestation adjusted birth weight (crude OR for the highest fifth $=1.38,95 \%$ CI 0.82 to 2.31 , adjusted OR $=1.55,95 \%$ CI 0.84 to 2.83 ), though the trend was not significant. When individual perinatal factors were adjusted for the corresponding perinatal factor of the co-twin the ORs decreased slightly but the result remained unchanged (table 2). The regression estimates of the perinatal factors in the co-twin showed 
Table 2 Multiple logistic regression of possible perinatal risk factors for asthma in 16 year old Finnish adolescents. Crude and adjusted odds ratios (OR) with $95 \%$ confidence intervals (CI) ${ }^{1}$

\begin{tabular}{|c|c|c|c|c|c|c|c|c|}
\hline Perinatal risk factors & $\begin{array}{l}\text { Proportion in } \\
\text { category and } \\
\text { total no. }\end{array}$ & $\begin{array}{l}\text { Occurrence of asthma } \\
\text { (\% and no. affected) }\end{array}$ & Crude OR & $95 \% C I$ & $\begin{array}{l}\text { Adjusted } \\
O R^{2}\end{array}$ & $95 \% C I$ & $\begin{array}{l}\text { Adjusted } \\
O R^{3}\end{array}$ & $95 \% C I$ \\
\hline \multicolumn{9}{|l|}{ Individual birth factors } \\
\hline \multicolumn{9}{|l|}{ Birth weight $(\mathrm{g})$} \\
\hline$<2000$ & $10.5 \%$ & $4.4 \%(21)$ & 1.0 & & 1.0 & & 1.0 & \\
\hline $2000-2499$ & $23.6 \%$ & $3.6 \%(38)$ & 0.82 & 0.45 to 1.50 & 0.78 & 0.40 to 1.51 & 0.73 & 0.36 to 1.90 \\
\hline $2500-2999$ & $38.2 \%$ & $3.5 \%(61)$ & 0.80 & 0.46 to 1.41 & 0.69 & 0.37 to 1.31 & 0.61 & 0.30 to 1.24 \\
\hline \multirow[t]{2}{*}{$\geqslant 3000$} & $27.7 \%$ & $4.6 \%(57)$ & 1.05 & 0.60 to 1.84 & 1.12 & 0.59 to 2.13 & 0.93 & 0.44 to 1.97 \\
\hline & $\mathrm{n}=4502$ & Test for trend ${ }^{4}$ & $\mathrm{p}=0.6$ & & $\mathrm{p}=0.4$ & & $\mathrm{p}=0.8$ & \\
\hline \multicolumn{9}{|c|}{ Ponderal index in quarters } \\
\hline-23.60 & $25.3 \%$ & $3.1 \%(35)$ & 1.0 & & 1.0 & & 1.0 & \\
\hline $23.61-25.30$ & $24.8 \%$ & $3.3 \%(36)$ & 1.02 & 0.64 to 1.63 & 1.02 & 0.60 to 1.74 & 1.01 & 0.58 to 1.74 \\
\hline $25.31-26.96$ & $24.8 \%$ & $3.5 \%(38)$ & 1.12 & 0.72 to 1.76 & 1.08 & 0.64 to 1.84 & 0.99 & 0.57 to 1.70 \\
\hline \multirow[t]{2}{*}{$26.97-$} & $25.2 \%^{5}$ & $5.9 \%(65)$ & 1.82 & 1.18 to 2.79 & 1.86 & 1.13 to 3.07 & 1.67 & 0.98 to 2.87 \\
\hline & $\mathrm{n}=4403$ & Test for trend & $\mathrm{p}<0.01$ & & $\mathrm{p}<0.01$ & & $\mathrm{p}<0.05$ & \\
\hline \multicolumn{9}{|l|}{ Apgar score } \\
\hline$\geqslant 7$ & $89.9 \%$ & $3.7 \%(122)$ & 1.0 & & 1.0 & & 1.0 & \\
\hline$<7$ & $\begin{array}{l}10.1 \% \\
\mathrm{n}=3710\end{array}$ & $4.8 \%(18)$ & 1.39 & 0.84 to 2.30 & 1.13 & 0.62 to 2.06 & 1.25 & 0.66 to 2.39 \\
\hline \multicolumn{9}{|c|}{ Neonatal hospitalisation } \\
\hline No & $70.5 \%$ & $3.7 \%(114)$ & 1.0 & & 1.0 & & 1.0 & \\
\hline Yes & $29.5 \%$ & $4.6 \%(60)$ & 1.24 & 0.88 to 1.75 & 1.17 & 0.79 to 1.74 & 1.06 & 0.60 to 1.88 \\
\hline & $\mathrm{n}=4406$ & & & & & & & \\
\hline \multicolumn{9}{|c|}{ Birth factors common to both members of the pair } \\
\hline \multicolumn{9}{|c|}{ Gestational age (weeks) } \\
\hline$<33$ & $7.1 \%$ & $3.9 \%(11)$ & 1.0 & & 1.0 & & & \\
\hline $33-36$ & $29.0 \%$ & $3.7 \%(42)$ & 0.94 & 0.43 to 2.04 & 0.88 & 0.39 to 1.99 & & \\
\hline $37-40$ & $60.6 \%$ & $4.0 \%(96)$ & 1.03 & 0.49 to 2.13 & 0.90 & 0.42 to 1.96 & & \\
\hline$>40$ & $3.3 \%$ & $4.6 \%(6)$ & 1.19 & 0.37 to 3.83 & 1.43 & 0.46 to 4.42 & & \\
\hline & $\mathrm{n}=3968$ & Test for trend & $\mathrm{p}=0.6$ & & $\mathrm{p}=0.8$ & & & \\
\hline \multicolumn{9}{|c|}{ Maternal age at birth of twins (years) } \\
\hline$<25$ & $31.4 \%$ & $5.1 \%(73)$ & 1.0 & & 1.0 & & & \\
\hline $25-30$ & $38.8 \%$ & $3.5 \%(62)$ & 0.67 & 0.46 to 0.99 & 0.71 & 0.45 to 1.11 & & \\
\hline \multirow[t]{2}{*}{$>30$} & $29.8 \%$ & $3.2 \%(44)$ & 0.62 & 0.41 to 0.94 & 0.75 & 0.46 to 1.23 & & \\
\hline & $\mathrm{n}=4578$ & Test for trend & $\mathrm{p}<0.05$ & & $\mathrm{p}=0.2$ & & & \\
\hline
\end{tabular}

${ }^{1}$ Regression results corrected by generalised estimating equations (GEE)

${ }^{2}$ OR adjusted for zygosity, birth order (A/B-twin), sex, number of older siblings, parental asthma, and maternal smoking.

${ }^{3}$ Additionally adjusted for the corresponding birth factor of the co-twin.

${ }^{4}$ Wald's statistic for trend in logistic regression.

${ }^{5}$ Percentages add up to $100.1 \%$ due to rounding.

patterns similar to those in the index twin but were not significant (data not shown). Among the co-twins within the highest fourth of the ponderal index, the OR for asthma was 1.50 (95\% CI 0.87 to 2.59 ) indicating that a high ponderal index is a risk factor on an individual level rather than due to shared environment.

In the univariate analysis of shared perinatal factors the risk of asthma increased with decreasing maternal age (table 2). The offspring of mothers under the age of 25 at the time of their birth were at a significantly higher risk for developing asthma than were the offspring of older mothers. Because both members of the pair share the values for common birth factors, adjustment for co-twin values was not performed.

Testing suggested interactions between parental asthma status and categorised ponderal index ( $\mathrm{p}$ for Wald statistic of the interaction term $=0.08$ ) and gestation adjusted birth weight (categorised as continuous $p=0.04$ and categorised $\mathrm{p}=0.10$ ). In the analysis stratified by parental asthma status the risk for asthma in adolescents with unaffected parents increased with increasing ponderal index ( $\mathrm{p}$ for trend $<0.01$ when adjusted for confounders), whereas among adolescents with asthmatic parent(s) a similar trend was found for gestation adjusted birth weight ( $\mathrm{p}$ for trend $<0.01$ when adjusted for confounders) (data not shown). In the latter families those with a higher ponderal index had, in addition, a higher risk for asthma (OR 2.33, 95\% CI 0.84 to 6.48) than did those with the lowest ponderal index. However, there was no significant trend and the confidence intervals included unity as there were few cases in each category (data not shown).

After assessment of the perinatal risk factors, non-perinatal factors were assessed separately. Because the occurrence of asthma in the offspring of farmers was distinct from that in any other occupational group, other occupational categories were pooled. Sex, hay fever in the adolescent, parental asthma, parental hay fever, sibship size, father's occupation, and maternal smoking were all associated with asthma (table 3). Because the ORs of adolescent's own smoking and exposure to ETS were close to unity, only maternal smoking among the smoking variables was included in the subsequent analysis. When non-perinatal variables were included in the same model, parental asthma, sibship size, and maternal smoking remained significant determinants of asthma, and further adjustment with adolescent's hay fever changed the ORs only slightly (table 3 ).

When significant perinatal and non-perinatal risk factors (ponderal index, neonatal hospitalisation, maternal age, sex, parental asthma, parental hay fever, number of older siblings, father's occupation, and maternal smoking) were combined in a single model, the following remained independent determinants of asthma: ponderal index, maternal smoking, parental asthma, and number of older siblings (table 4). The model additionally adjusting for hay fever in the adolescent showed a similar result except for sibship size which was 
Table 3 Multiple logistic regression of non-perinatal risk factors for asthma among 16-year-old Finnish adolescents. Crude and adjusted odds ratios (OR) with $95 \%$ confidence intervals $(C I)^{1}$

\begin{tabular}{|c|c|c|c|c|c|c|c|c|}
\hline Non-perinatal risk factors & $\begin{array}{l}\text { Proportion of } \\
\text { category and total } \\
\text { no. }\end{array}$ & $\begin{array}{l}\text { Occurrence of } \\
\text { asthma (\% and } \\
\text { no. affected) }\end{array}$ & $\begin{array}{l}\text { Crude } \\
\text { OR }\end{array}$ & $95 \% C I$ & $\begin{array}{l}\text { Adjusted } \\
O^{2}\end{array}$ & $95 \% C I$ & $\begin{array}{l}\text { Adjusted also } \\
\text { for hay fever } \\
(O R)^{3}\end{array}$ & $95 \% C I$ \\
\hline \multicolumn{9}{|c|}{ Individual non-perinatal factors } \\
\hline \multicolumn{9}{|c|}{ Sex } \\
\hline Male & $47.8 \%$ & $4.7 \%(120)$ & 1.0 & & 1.0 & & 1.0 & \\
\hline Female & $\begin{array}{l}52.2 \% \\
\mathrm{n}=4578\end{array}$ & $3.2 \%(77)$ & 0.72 & 0.52 to 0.99 & 0.81 & 0.57 to 1.17 & 0.96 & 0.63 to 1.46 \\
\hline \multicolumn{9}{|c|}{ Hay fever in the adolescent } \\
\hline No & $89.1 \%$ & $2.0 \%(79)$ & 1.0 & & & & & \\
\hline Yes & $\begin{array}{l}10.9 \% \\
\mathrm{n}=4496\end{array}$ & $15.7 \%(77)$ & 8.60 & 5.93 to 12.47 & & & & \\
\hline \multicolumn{9}{|c|}{ Non-perinatal factors common to both members of the pair } \\
\hline \multicolumn{9}{|c|}{ Parental asthma } \\
\hline No & $92.1 \%$ & $3.2 \%(107)$ & 1.0 & & 1.0 & & 1.0 & \\
\hline Yes & $\begin{array}{l}7.9 \% \\
\mathrm{n}=3682\end{array}$ & $14.8 \%(43)$ & 5.34 & 3.53 to 8.08 & 4.95 & 3.08 to 7.96 & 4.41 & 2.49 to 7.79 \\
\hline \multicolumn{9}{|l|}{ Parental hay fever } \\
\hline No & $71.2 \%$ & $3.2 \%(88)$ & 1.0 & & 1.0 & & 1.0 & \\
\hline Yes & $\begin{array}{l}28.8 \% \\
\mathrm{n}=3824\end{array}$ & $6.2 \%(60)$ & 1.97 & 1.37 to 2.83 & 1.23 & 0.81 to 1.89 & 1.03 & 0.64 to 1.67 \\
\hline \multicolumn{9}{|l|}{ Number of older siblings } \\
\hline $0-1$ & $77.6 \%$ & $4.4 \%(136)$ & 1.0 & & 1.0 & & 1.0 & \\
\hline $2+$ & $\begin{array}{l}22.4 \% \\
\mathrm{n}=3990\end{array}$ & $2.7 \%(24)$ & 0.60 & 0.38 to 0.95 & 0.60 & 0.37 to 0.99 & 0.71 & 0.41 to 1.24 \\
\hline \multicolumn{9}{|l|}{ Father's occupation } \\
\hline Farmer & $11.7 \%$ & $2.2 \%(10)$ & 1.0 & & 1.0 & & 1.0 & \\
\hline Other & $\begin{array}{l}88.3 \% \\
n=3908\end{array}$ & $4.3 \%(147)$ & 1.98 & 1.04 to 3.79 & 1.57 & 0.79 to 3.15 & 1.06 & 0.51 to 2.21 \\
\hline \multicolumn{9}{|l|}{ Maternal smoking } \\
\hline Never & $52.5 \%$ & $3.2 \%(76)$ & 1.0 & & 1.0 & & 1.0 & \\
\hline Ever & $\begin{array}{l}47.5 \% \\
\mathrm{n}=4538\end{array}$ & $4.7 \%(101)$ & 1.49 & 1.07 to 2.08 & 1.49 & 1.02 to 2.18 & 1.48 & 0.97 to 2.25 \\
\hline
\end{tabular}

${ }^{1}$ Regression results corrected by generalised estimating equations (GEE).

${ }^{2}$ Adjusted for other factors shown in the table except for hay fever in the adolescent.

${ }^{3}$ Additionally adjusted for hay fever in the adolescent.

Table 4 Perinatal and non-perinatal risk factors for asthma among 16 year old Finnish adolescents combined in a single model ${ }^{1,2}$

\begin{tabular}{llll}
\hline & \multicolumn{2}{l}{$\begin{array}{l}\text { Risk of asthma } \\
(n=3285)\end{array}$} & $\begin{array}{c}\text { Attributable } \\
\text { proportion }^{3}\end{array}$ \\
\cline { 2 - 3 } Risk factors & OR & $95 \%$ CI & \\
\hline $\begin{array}{l}\text { Ponderal index in quarters } \\
\quad \text { Lowest }\end{array}$ & 1.0 & & \\
$\quad$ 2nd & 0.97 & 0.57 to 1.67 & \\
3rd & 0.94 & 0.55 to 1.61 & \\
$\quad$ Highest & $1.74^{4}$ & 1.07 to 2.85 & $17 \%$ \\
$\begin{array}{l}\text { Maternal smoking } \\
\text { Never }\end{array}$ & 1.0 & & \\
$\quad \begin{array}{l}\text { Ever } \\
\text { Parental asthma }\end{array}$ & 1.59 & 1.09 to 2.31 & $25 \%$ \\
$\quad$ No & 1.0 & & \\
$\quad$ Yes & 5.25 & 3.39 to 8.12 & $23 \%$ \\
Number of older siblings & & $32 \%$ \\
$\quad 0-1$ & 1.0 & & \\
$2+$ & 0.61 & 0.38 to 0.99 & \\
\hline
\end{tabular}

${ }^{1}$ Selection of variables by backward stepwise logistic regression. ${ }^{2}$ Regression results corrected by generalised estimating equations (GEE)

${ }^{3}$ Proportion of cases due to exposure to the risk factor among all those exposed and unexposed. ${ }^{26}$

${ }^{4}$ Test for trend $\mathrm{p}<0.01$.

replaced by neonatal hospitalisation (OR 1.60,
95\% CI 1.00 to 2.47 ) (data not shown).

Inclusion of subjects with missing data for the independent variables (perinatal and nonperinatal) in the analysis as an additional category for each variable did not change the results.

Among asthma discordant $\mathrm{MZ}$ pairs ( $\mathrm{n}=$ 32) twins with asthma tended to have a lower birth weight, lower ponderal index, and lower Apgar score than did their unaffected co-twins, whereas among asthma discordant $\mathrm{DZ}$ pairs ( $\mathrm{n}$ $=101$ ) twins with asthma had a higher birth weight and ponderal index than the unaffected co-twins (table 5). The difference in ponderal index among $\mathrm{DZ}$ discordant pairs was significant, but the differences between $\mathrm{MZ}$ and $\mathrm{DZ}$ pairs were not (table 5). There were no significant associations between categorised birth weight, ponderal index, gestation adjusted birth weight, or neonatal hospitalisation and the disease status in the asthma discordant pairs overall or when stratified by zygosity (data not shown).

Table 5 Comparison of individual birth factors within asthma discordant twin pairs by zygosity. Median differences with non-parametric $95 \%$ confidence intervals (CI)

\begin{tabular}{|c|c|c|c|c|c|c|}
\hline \multirow[b]{2}{*}{ Perinatal factors } & \multicolumn{3}{|c|}{$M Z$ intrapair difference } & \multicolumn{3}{|c|}{$D Z$ intrapair difference } \\
\hline & $\begin{array}{l}\text { Median } \\
\text { (no. of pairs) }^{2}\end{array}$ & $95 \% C I$ & $p$ value $^{3}$ & $\begin{array}{l}\text { Median } \\
\text { (no. of pairs) }^{2}\end{array}$ & $95 \% C I$ & p value ${ }^{3}$ \\
\hline Birth weight (g) & $-135(32)$ & -240 to +100 & 0.26 & $+50(101)$ & -40 to +150 & 0.22 \\
\hline Ponderal index $\left(\mathrm{kg} / \mathrm{m}^{3}\right)$ & $-0.14(32)$ & -1.22 to +0.91 & 0.84 & $+0.59(100)$ & -0.14 to +1.12 & 0.03 \\
\hline Apgar score & $0(25)$ & 0 & 0.60 & $0(82)$ & 0 & 0.49 \\
\hline
\end{tabular}

${ }^{1}$ The differences between $\mathrm{MZ}$ and $\mathrm{DZ}$ with Wilcoxon rank sum test were not significant.

${ }^{2}$ Median of the intrapair differences (affected minus unaffected).

${ }^{3}$ Wilcoxon signed rank test. 


\section{Discussion}

The major strength of this study is that it was conducted in a nationwide population based twin cohort with high response rates. ${ }^{19}$ This minimises selection bias, except for the effect due to twinning. In addition, because the FinnTwin 16 study assessed multiple aspects of the health and behaviour of adolescents, bias towards over-reporting of allergic disorders is unlikely. Multiple birth itself has been suggested to decrease the risk for asthma and hay fever, ${ }^{5}$ but very few studies have compared the occurrence of asthma in twins with that in singletons. However, the prevalence rates for asthma and hay fever among Finnish adolescent singletons in studies which used methods similar to ours have been very similar to those among the twins of this study. ${ }^{19}$ 29-31

Among adolescent twins there was no apparent association between the occurrence of asthma and absolute birth weight, although those at the extremes of birth weight had slightly higher ORs than those with intermediate birth weights. Previous studies have found a negative association between birth weight and asthma even until young adulthood, ${ }^{4-632}$ but a lack of association has also been reported in a large cohort study. ${ }^{7}$ Low birth weight may be due to premature birth, inadequate nutrient supply to the fetus, or multiple pregnancy. Prematurity with its pulmonary complications has been reported to contribute to an increased risk for wheezing illness, particularly in childhood. ${ }^{8}$ In twins, growth retardation in the third trimester of pregnancy is a common cause of lower birth weight. ${ }^{33}$ With such a large proportion of low birth weights among twins, one would expect a higher rate of asthma if the birth weight in itself was a cause of asthma. However, maturation, especially of the lungs and central nervous system, takes place at the same stage of pregnancy in twins as in singletons, if not earlier, ${ }^{16}$ and for most twins the catch-up growth after birth is often rapid and is complete by school age. ${ }^{33}$ Birth weight may be an indicator of another underlying cause for asthma, or there may be mechanisms in the maturation and growth of twins which are still unknown and may be protective against the development of asthma among twins.

A novel finding in this study was the increasing risk for asthma with increasing ponderal index. Comparison of our result with other studies is difficult as only a few of the previous studies on the perinatal determinants of asthma have applied adjusted measures of birth weight. Among almost 900 adolescents from New Zealand a head circumference of $37 \mathrm{~cm}$ or over was the only factor predictive of asthma among several perinatal crude and ratio measures including the ponderal index. ${ }^{2}$ In the study by Fergusson et al the lack of association between ponderal index and asthma may have been due to a smaller sample size and different distribution of birth characteristics and asthma (13-27\% had asthma, depending on the definition). However, their finding of large head circumference is in accordance with our finding on ponderal index, since both measures indicate advanced fetal growth requiring a well functioning placenta and a nutrient surplus. In both studies the effect appeared independent since several individual, familial, and social factors were accounted for. A similar association between adjusted birth weight and asthma among both adolescents with (gestation adjusted birth weight) and without a parental history of asthma (ponderal index) may suggest that the effect of adjusted birth weight is independent of the genetic background of asthma.

Because others have suggested a positive association between birth factors and hay fever, ${ }^{52}$ our observations may reflect the well known association of asthma and atopy in adolescence. Unfortunately, clinical measurements such as serum IgE were not available in the present nationwide cohort of adolescents. However, the association between ponderal index and asthma remained after adjustment for hay fever. Another possible explanation is that a high ponderal index may predict obesity in adolescence ${ }^{34}$ which, in turn, may be associated with asthma and bronchial reactivity. ${ }^{635}$ However, Shaheen et al found an association between low birth weight and asthma on the one hand and, on the other, between a high body mass index and asthma at 26 years of age. ${ }^{6}$ The association of birth weight, later body weight, and asthma deserves further study and longitudinal studies are needed to tease out causal relationships.

The result of the discordant pair analysis supports the logistic regression analysis of perinatal factors on all pairs. In $\mathrm{DZ}$ pairs the ponderal index was significantly higher in the affected twin, indicating an association between ponderal index and asthma. Further, the greater intrapair difference in $\mathrm{DZ}$ twins than in $M Z$ twins may indicate a genetic contribution to the association between ponderal index and asthma. On the other hand, the finding that the intrapair difference between birth weight and ponderal index was negative in $M Z$ pairs and positive in $\mathrm{DZ}$ pairs suggests that the mechanisms between birth characteristics and asthma may differ in MZ and DZ twins. However, because of the relatively small number of asthma-discordant pairs, the results of the discordant-pair analysis are vulnerable to recall bias with respect to birth measurements. This bias would generally tend to obscure relationships. The apparent lack of an association in the $M Z$ pairs should therefore be interpreted with caution.

Maternal smoking increased the risk for asthma in the adolescents by over $50 \%$. This is in agreement with current knowledge of the effect of parental smoking on the risk of asthma in their children. ${ }^{36}$ Maternal smoking in pregnancy impairs the growth of the fetus ${ }^{37}$ and may contribute further to the increased risk for wheezing in early childhood. ${ }^{7}$ It is practically impossible to make a complete distinction between the effects of smoking during pregnancy and smoking before or after, as most smoking mothers continue to smoke throughout pregnancy. Even with a relatively crude measure of maternal smoking (never versus ever) an association with asthma in the adoles- 
cents was apparent. This result may be accounted for by smoking during pregnancy but, alternatively, it may indicate some unmeasured life style factor. This, however, receives no support from the finding that the other smoking variables analysed-environmental tobacco smoke at home and the adolescents' own smoking-showed no association with asthma in these adolescents.

In this study of adolescent twins hay fever in the adolescent and parental asthma were the strongest determinants of asthma at the age of 16 as judged by the odds ratios. However, at the population level the effect of a risk factor depends also on the prevalence of the exposure-that is, how common is the risk factor. Attributable proportion combines the effects of both the relative risk and the prevalence of the exposure. The attributable proportion of high ponderal index, almost as large as that of parental asthma, suggests that, at the population level, the effect of the ponderal index on the risk of asthma is of the same magnitude as the effect of parental asthma.

This study was supported by grants from Rauha and Juho Ahokas' Foundation, The Finnish Anti-Tuberculosis Association Foundation, Ida Montin's Foundation, and the Finnish Association of Chest Physicians. FinnTwin16 is supported by the United States National Institutes of Health (AA 08315) and by the Academy of Finland (JK, grants \#42044, 38332). MR was supported by the Helsinki University Central Hospital research funds.

Conflict of interests: None

1 Barker DJP, Godfrey KM, Fall C, et al. Relation of birth weight and childhood respiratory infection to adult lung function and death from chronic obstructive airways disease. BMf 1991;303:671-5.

2 Fergusson DM, Crane J, Beasley R, et al. Perinatal factors and atopic disease in childhood. Clin Exp Allergy 1997;27: 1394-401.

3 Rona RJ, Gulliford MC, Chinn S. Effects of prematurity and intra-uterine growth on respiratory health and lung and intra-uterine growth on respiratory heal
function in childhood. BMF 1993;306:817-20.

4 Seidman DS, Laor A, Gale R, et al. Is low birth weight a risk factor for asthma during adolescence? Arch Dis Child 1991; 66:584-7.

5 Bråbäck L, Hedberg A. Perinatal risk factors for atopic disease in conscripts. Clin Exp Allergy 1997;28:936-42.

6 Shaheen SO, Sterne JAC, Montgomery SM, et al. Birth weight, body mass index and asthma in young adults. Thorax 1999;54:396-402.

7 Lewis S, Richards D, Bynner J, et al. Prospective study of risk factors for early and persistent wheezing in childhood. Eur Respir F 1995;8:349-56.

8 von Mutius E, Nicolai T, Martinez FD. Prematurity as a risk factor for asthma in preadolescent children. 7 Pediatr 1993 123:223-9.

9 Frischer T, Kuehr J, Meinert R, et al. Risk factors for childhood asthma and recurrent wheezy bronchitis. Eur F Pediatr 1993;152:771-5.

10 Strachan DP, Butland BK, Anderson HR. Incidence and prognosis of asthma and wheezing illness from early childprognosis of asthma and wheezing ilness from early child1195-9.

11 Strachan DP, Taylor EM, Carpenter RG. Family structure, neonatal infection, and hay fever in adolescence. Arch Dis Child 1996;74:422-6.

12 Olesen AB, Ellingsen AR, Olesen $\mathrm{H}$, et al. Atopic dermatitis and birth factors: historical follow up by record linkage. BMF 1997;314:1003-8.
13 Godfrey KM, Barker DJP, Osmond C. Disproportionate fetal growth and raised IgE concentration in adult life. Clin Exp Allergy 1994;24:641-8.

14 Taffel SM. Demographic trends in twin births: USA. In: Keith LG, Papiernik E, Keith DM, Luke B, eds. Multiple pregnancy: epidemiology, gestation and perinatal outcome. Carnforth: The Parthenon Publishing Group, 1995: 133-43.

15 Powers WF, Kiely JL, Fowler MG. The role of birth weight, gestational age, race and other infant characteristics in twin intra-uterine growth and infant mortality. In: Keith LG, Papiernik E, Keith DM, Luke B, eds. Multiple pregnancy: epidemiology, gestation and perinatal outcome. Carnforth: The Parthenon Publishing Group, 1995: 163-74.

16 Amiel-Tison C, Gluck L. Fetal brain and pulmonary adaptation in multiple pregnancy. In: Keith LG, Papiernik E, Keith DM, Luke B, eds. Multiple pregnancy: epidemiology, gestation and perinatal outcome. Carnforth: The Parthenon Publishing Group, 1995: 585-97.

17 Friedman SA, Schiff E, Kao L, et al. Do twins mature earlier than singletons? Results from a matched cohort study. Sixty-fourth annual meeting of the Central Association of Obstetricians and Gynecologists, 1996, Houston, Texas. Am 7 Obstet Gynecol 1997;176:1193-6.

18 Martin N, Boomsma D, Machin G. A twin-pronged attack on complex traits. Nature Genet 1997;17:387-92.

19 Laitinen T, Räsänen M, Kaprio J, et al. Importance of genetic factors in adolescent asthma: a population-based twin-family study. Am $\mathcal{F}$ Respir Crit Care Med 1998;157: 1073-8.

20 Aarnio M, Kujala UM, Kaprio J. Associations of healthrelated behaviors, school type and health status to physical activity patterns in 16 year old boys and girls. Scand $\mathcal{F}$ Soc Med 1997;25:156-67.

21 Vesterinen E, Kaprio J, Koskenvuo M. Prospective study of asthma in relation to smoking habits among 14729 adults. Thorax 1988;43:534-9.

22 Aarnio M, Winter T, Kujala UM, et al. Familial aggregation of leisure-time physical activity: a three generation study. Int f Sports Med 1997;18:549-56.

23 Seidman DS, Slater PE, Ever-Hadani P, et al. Accuracy of mothers' recall of birthweight and gestational age. $\mathrm{Br} \mathcal{F}$ Obstet Gynaecol 1987;94:731-5.

24 Health Services Yearbook of National Board of Health 1978-1979. Helsinki: National Board of Health, 1980.

25 Cole T, Henson GL, Tremble JM, et al. Birthweight for length:ponderal index, body mass index or Benn index? Ann Hum Biol 1997;24:289-98.

26 Rothman KJ. Measures of effect. Modern epidemiology. Boston: Little, Brown and Company, 1986: 35-40.

27 Duffy DL, Mitchell CA, Martin NG. Genetic and environmental risk factors for asthma - a cotwin-control study. Am 7 Respir Crit Care Med 1998;157:840-5.

28 Liang KY, Zeger S. Longitudinal data analysis using generalized linear models. Biometrika 1986;73:13-22.

29 Rimpelä AH, Savonius B, Rimpelä MK, et al. Asthma and rhinitis among Finnish adolescents in 1977-1991. Scand $\mathcal{F}$ Soc Med 1995;23:60-5.

30 Räsänen M, Laitinen T, Kaprio J, et al. Hay fever: a Finnish nation-wide study of adolescent twins and their parents. Allergy 1998;53:885-90.

31 Remes ST, Korppi M, Remes K, et al. Prevalence of asthma at school age: a clinical population-based study in eastern Finland. Acta Paediatr 1996;85:59-63.

32 Svanes C, Omenaas E, Heuch JM, et al. Birth characteristics and asthma symptoms in young adults: results from a population-based cohort study in Norway. Eur Respir $\mathfrak{f}$ 1998;12:1366-70.

33 Wilson RS. Twin growth: initial deficit, recovery, and trends in concordance from birth to nine years. Ann Hum Biol 1979;6:205-20

34 Rasmussen F, Johansson $M$. The relation of weight, length and ponderal index at birth to body mass index and overweight among 18-year-old males in Sweden. Eur f Epidemiol 1998;14:373-80.

35 Luder E, Melnik TA, DiMaio M. Association of being overweight with greater asthma symptoms in inner city black and Hispanic children. 7 Pediatr 1998;132:699-703.

36 Cook DG, Strachan DP. Parental smoking and prevalence of respiratory symptoms and asthma in school age children. Thorax 1997;52:1081-94.

37 Cliver SP, Goldenberg RL, Cutter GR, et al. The effect of cigarette smoking on neonatal anthropometric measurements. Obstet Gynecol 1995;85:625-30. 